
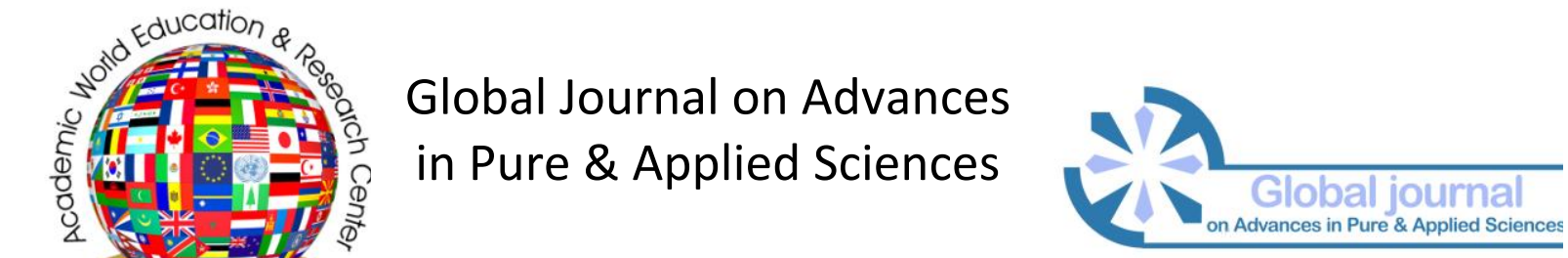

Issue 7 (2016) 90-94

Selected Paper of 2nd World Conference on Health Sciences (H-SCl 2015)

30 April-02 May 2015 Efes Sürmeli Hotel \& Convention Center - İzmir, Kuşadası, Turkey

\title{
The Correlation Between Manners of Conflict and Manners of Communication of Nurses in Emergency Room. Case Study: A Study of Conflict Welding Communication
}

Umran Celik Barmakci *, Aksehir Kadir Yallagoz School of Health, Yıldırım Beyazıt Training and Research Hospital Training Nurse, Selcuk University, Turkey.

Funda Ozpulat, Aksehir Kadir Yallagoz School of Health, Yıldırım Beyazıt Training and Research Hospital Training Nurse, Selcuk University, Turkey.

\section{Suggested Citation:}

Barmakci, U., C. \& Ozpulat, F. (2016). The Correlation Between Manners of Conflict and Manners of Communication of Nurses in Emergency Room. Case Study: A Study of Conflict Welding Communication, Global Journal on Advances in Pure \& Applied Sciences. [Online]. 07, pp 90-94. Available from: www.propaas.eu

Received November 04, 2014; revised December 06, 2014; accepted March 07, 2015.

Selection and peer review under responsibility of Prof. Dr. Fahrettin Sadikoglu, Near East University.

(C)2016 Academic World Education \& Research Center. All rights reserved.

\begin{abstract}
The concept of "conflict" is not only an interest of area of organizational psychology, but it is also a research area of psychology, sociology, anthropology, economics, and some other disciplines. Due to the increase of demands for societies of health care day-to-day, the analysis of the elements which effect the usage of hospitals efficiently and effectively also comes into prominence. One of those is the phenomenon of "conflict". Since hospitals are complex structures, the reasons of conflicts that may occur are so varied. There may sometimes be numerous reasons behind a conflict case at a unit. Emergency room is one of the units where the conflicts at hospitals frequently happen. In order to manage a conflict in emergency room, it comes into prominence to diagnose the conflict, to make the necessary intervention, and to bring out the reasons of the conflict. In this case study, the conflict happens as a chain of events by taking a report of a nurse who will come to seizure without informing the other responsible nurse and declaring to the other responsible nurse that four colleagues of the other sentry nurse have not come. The reason of happening of the conflict is the manner of unclear communication. The nurse who will not come to her seizure by taking a report does not inform that and she keeps her taking report secret. The conflict is terminated by win-win logic, a method of problem solving, of the
\end{abstract}

* ADDRESS FOR CORRESPONDENCE: Umran Celik Barmakci, Aksehir Kadir Yallagoz School of Health, Yıldırım Beyazıt Training and Research Hospital Training Nurse, Selcuk University, Turkey. E-mail address: umran971@hotmail.com 
Barmakci, U., C. \& Ozpulat, F. (2016). The Correlation Between Manners of Conflict and Manners of Communication of Nurses in Emergency Room. Case Study: A Study of Conflict Welding Communication, Global Journal on Advances in Pure \& Applied Sciences. [Online]. 07, pp 9094. Available from: $\underline{w w w . p r o p a a s . e u}$

responsible nurse and by participating of other workers in this issue. Mutual clear communication is used and the main reason of the problem is identified as "communication problem". As a result, it is inferred that communication problems cause hindering work, forming a platform of conflicts, and wasting time. While the conflict is being terminated, communication problems between numerous people are removed by using correct communication ways and it is given a lead to obtain a better communication platform in the organization. Having less problems due to taking care of communication in emergency room after this event shows that this conflict has been resulted in positive outcomes.

Keywords: Emergency Room, Nursing, Conflict, Manners of Communication, Case Study.

\section{Introduction}

Besides occurring in too different places and levels, conflict generally means "the hardships an individual or a group go through while choosing an option, and the breakdown in decision making mechanisms, as a result of this" [4]. Conflict is not only a concept which only management or organizational psychology emphasize but also a concept which is included in sociology, psychology, anthropology, economy and other disciplines' study fields [3].

Because of the rising need of the societies for the health services, the analysis of the elements that affect the efficient usage of hospitals has also gained importance. One of these is the conflict phenomenon. As hospitals is one of the most complex organizations, they have a great potential of conflict. Organizational conflict from the hospital organizations' point of view can be seen as a broad concept which especially includes the disagreements, role conflicts and uncertainty between personnel during the treatment process, and the other conflict factors [5].

As hospitals has a complex structure, the reasons of conflicts are also different. Sometimes, there can be many reasons behind a conflict example in one of the units. Knowing the factors causing conflicts is an important step for the solution [1]. One of the units in which conflicts occur more often than the others is emergency units [2]. Emergency units are the places where the members of society and hospitals come together and communicate the most. The obligation to serve patients in a quick, right and continuous way require hospitals to be different than other fields of medicine in terms of physical structure and personnel power [6]. Emergency units take place on a central location which refers patients to other units of the hospital, besides being the place where medical response is the best and the only place which includes all types of response [2].

The reasons such as the complex and dynamic structure of emergency units, emergent works, workload, the education level difference among the nurses, perception differences because of personal diversities, insufficient information exchange among units, perception problems among units because of the communication breakdowns, lack of work definition, lack of decision agreement, and lack of job satisfaction creates lack of communication or conflicts among the personnel. To be able to spot the conflict, respond as needed, and reveal the reasons of conflict gains great importance.

The Correlation Between Manners Of Conflict And Manners Of Communication Of Nurses In Emergency Room Case Study: A Study Of Conflict Welding Communication

The occurrence of conflict has happened in a chain of events when a nurse who is supposed to be on duty received report without informing the nurse in charge, and the other nurse who is on duty informed the nurse in charge about the fact that her friend is missing.

Hour of work finishes at 16 o'clock. The nurse in charge has not left the emergency unit to be able to finish some of her works. To be able to solve the problem, she has checked all the lists of units, and as a result she has decided to bring down the number of nurses in primary intensive care unit from 4 to 3 , and assign that nurse to observation room. The nurse in charge has spoken to her friends on phone because of the overload of works at that moment. She has stated that she did not want to see such an event but one of the nurses had received report without her knowledge, and for this reason 
Barmakci, U., C. \& Ozpulat, F. (2016). The Correlation Between Manners of Conflict and Manners of Communication of Nurses in Emergency Room. Case Study: A Study of Conflict Welding Communication, Global Journal on Advances in Pure \& Applied Sciences. [Online]. 07, pp 90- 
Barmakci, U., C. \& Ozpulat, F. (2016). The Correlation Between Manners of Conflict and Manners of Communication of Nurses in Emergency Room. Case Study: A Study of Conflict Welding Communication, Global Journal on Advances in Pure \& Applied Sciences. [Online]. 07, pp 9094. Available from: www.propaas.eu

deal. The sides solved the problem by using the communication techniques and maintaining a good communication without getting any help from outside, and this environment was enough to be able to solve the problem. The fact that the number of problems about the lack of communication has diminished over time has showed that the method was beneficial.

\section{Conclusion and Review}

The main reason of the conflict in this case study is the unclear type of communication. The nurse who received report to skip her duty did not inform the nurse in charge about that and kept it as secret. If the nurse had informed the nurse in charge about that, this problem would be prevented before it even existed. The usage of the right communication types could have prevented such a problem.

The nurse in charge explained the reason of the problem by using an open communication when she called the intensive care unit, but B.Ş, who answered the phone first, used a wrong tone and told that she would not go to observation room, and started an active conflict. The person involved in active conflict could not understand what was said to her and would not listen to what was said, and this led to the extension of the conflict. The fact that B.S did not mention anything about this situation to her friends made the conflict spread among her friends as well. L.S who did not go to the observation room was also using a wrong type of communication. Also, as she had some problems with the nurse in charge in the past, she entered into an open conflict with her. The nurse in charge tried to stay calm during the process, used an open communication style, and demanded a meeting to solve the problem. She maintained her communication style during the meeting as well, and told that the petition was sent but not approved while thinking that there was still some lack of communication. This made the nurses understand that there was not an intentional behaviour in this situation.

Also, there was a vertical conflict happening with the head nursery's assistant. The head nursery's assistant talked down to others, and this created a passive conflict between her and the nurse in charge. The nurse in charge experienced a conflict in herself because she tried to repress her fury, and the problems with the head nursery's assistant continued.

The conflict has been solved by the nurse in charge through win win negotiation with the participation of the other personnel. Interactive communication was used and it has been understood that the real reason of the problem is the lack of communication. If the conflict had not been solved with the right approach, the problem could go on and on, and could even prevent the personnel from doing their works. In the end, it has been seen that the communication problems caused conflicts, time losses and the disruption of work. While the conflict has been solved, the right communication styles were used, which helped to remove the problems and created a way to maintain a nice communication environment within the organization. After that incident, the care for the good communication environment in the emergency unit shows that this conflict ended up with positive outcomes.

\section{Suggestions}

Regardless of the type of organization, it is important to provide right and efficient communication. Emergency units have a complex and dynamic structure. For this reason, the necessity to maintain a right kind of communication is much more important. The communication should be in efficient levels, and communication should be valued in these times we call communication age.

In this case study, it can be seen that communication education for the personnel is really important. For this reason, there should be in-service training and seminars for personnel in terms of communication. Also, the relationship between communication and work performance should be 
Barmakci, U., C. \& Ozpulat, F. (2016). The Correlation Between Manners of Conflict and Manners of Communication of Nurses in Emergency Room. Case Study: A Study of Conflict Welding Communication, Global Journal on Advances in Pure \& Applied Sciences. [Online]. 07, pp 9094. Available from: www.propaas.eu

explained to the personnel. The communication should be backed up with regular meetings, and the lack of knowledge should be satisfied. The open and respectful communication among the personnel should be supported. Active type of communication should affect the work performance in a positive and meaningful way. Managers should manager the individual communication. Individual communication should be handled as a supervisory activity. The removal of the lack of communication in the emergency unit and the development of right kind of communication among nurses will contribute to the development of communication between the nurses and the patients, which leads to the satisfaction of the patients. Also, the development of conflict management skills of personnel from every level helps the organization realize its targets. As a result, it should be understood that communication, conflict, conflict management, and communication styles is very important for an organization, and everybody, personnel or manager, should comprehend the importance of these. The knowledge and skills related to this topic can reach to higher levels with the support of education.

\section{References}

[1] Akca, C., \& Erigüc, G. (2006). A Research Devoted to the Reasons of Conflict Between Hospital Staff and Their Managers and Co-workers. Hacettepe Journal of Health Agency, 127-153.

[2] Asplin, Br, Magid, Dj, Rhodes, Kv, Solberg, Li, Lurie, N, \& Camargo, Ca. (2003). A Conceptual Model of Emergency Department Crowding. Ann Emerg Med 2003, 42, 173-80.

[3] Asunakutlu, T., \& Safran, B. (2004). A Research Devoted to the Conflicts Arising from Cultural Differences (Marmaris Tourism Sector Sample). Dokuz Eylul University Journal of Social Sciences Institution, 6(1), 2649.

[4] Can, H. (2002). Organization and Management. $6^{\text {th }}$ print. Political Bookstore, Ankara.

[5] Ocak, S., Gider, O., Top, M., Şahin, B., \& Tarcan, M. (2004). A Research Devoted to Role Confusion among Nurses in Muğla State Hospital Modern Hospital Management, 54-56.

[6] Kilicaslan, I., Bozan, H., Oktay, C., \& Goksu, E. (2005). The Demographic Features of Patients Getting in Touch with Emergency Unit in Turkey. Journal of Turkey Emergency Medicine, 5(1), 5-13. 